\title{
The General Trends in Researches on Educational Technologies in Turkey
}

\author{
Baris Sezer \\ Department of Medical Education and Informatics, Faculty of Medicine \\ University of Hacettepe, 06100 Ankara, Turkey \\ E-mail: barissezer13@hotmail.com
}

Received: July 2, 2012

Accepted: July 26, 2013

Published: August 1, 2013

doi:10.5296/jse.v3i3.3948

URL: http://dx.doi.org/10.5296/jse.v3i3.3948

\begin{abstract}
This study has carried out a general evaluation of the articles published in the field of educational technology within the last two years in four journals circulating in Turkey. 263 articles in total have been identified in the Turkish Online Journal of Educational Technology, the Journal of Educational Technologies Researches, Contemporary Educational Technology and Educational Technology Theory and Practice journals in this field and these articles have been examined. The articles have been assessed in terms of style, content and method. The results show that two out of around every three studies have focused on material (material creation, development, application and assessment). Three out four studies have been done as review type. About half of the research has been conducted on university students as respondents. Moreover, three in every four studies have employed quantitative paradigm.
\end{abstract}

Keywords: Educational technology, Trends and issues, Journals, Turkey 


\section{Introduction}

Technology affects to a great extent the education as in many areas of our lives. Whenever a new technological innovation comes up, there emerges research on how to make use of that innovation in education in terms of planning, managing, application of the technology. Technology is a rational discipline designed by the human in order to establish superiority over the nature by using the science. The years when the concept of educational technology was defined as the utilization of tools and materials in education are well past. Now the educational technology encompasses numerous subjects and issues from human-technology interaction to performance technologies from computed assisted education to virtual education. According to Alkan (1997), educational technology is the work of design, implementation, assessment and development of learning-teaching processes. As will be seen from this definition, technology of education has a significant function for putting the theories formed in the field of educational sciences and thus development of applications. Correct understanding of the concept of educational technology by notably researchers in the new millennium can only be possible by knowing how the research on educational technologies are conducted and what kind of conclusions are deducted. The most valid way, perhaps, for this is the extensive and detailed examination of the studies made in the field of educational technology. Throughout the history; definition, limits of and areas influenced by the educational technologies have varied. In this context, the research subjects, study areas of and methods used in the research on educational technologies have during the course of time differed. Therefore, investigation into the academic studies in the field of educational technologies made in our country will reveal significant information in determination of the place of and research trends in this field.

The educational technologies have lastly been defined by the Association for Educational Communications and Technology [AECT]. According to AECT (2004), educational technology is the study and ethical practice of facilitating learning and improving performance by creating, using, and managing appropriate technological processes and resources. On the other hand, the educational technologies is a field that does not have a definition mutually agreed upon and it does not have clearly defined boundaries either. In this situation, studies oriented at finding out the trends in this field provides a great deal of information on the progress of the field and which subjects are being studied.

Looking at the literature, the leading studies conducted to establish the trends in the research on educational technologies are those studies of Caffarella and Sachs (1999). The researchers examined some trends and patterns in doctorate theses completed in the USA and published these trends in certain time intervals. According to this study, the below given trends are observed in doctorate theses completed between 1977 and 1998:

- The subjects mostly examined between these years are use of computers in education, design of educational software, individual differences and efficiency of computers in education.

- New technologies frequently affect the research topics selected. 
- Media comparison studies during this period decreased 5\% and employment of qualitative research methods increased.

Another trend research made in the field of educational technologies is a document analysis carried out by Hew, Kale and Nari in 2007. The researchers in this study examined 340 experimental research articles published in Educational Technology Research \& Development journal between 2000 and 2004 in terms of their subject, research method applied, data collection methods and research circles and found the following results.

- Media, learning psychology, approaches on educational design and assessment methods are the research topics studies most.

- The most favored research method is descriptive research methods in these studies.

- The participations have been mostly chosen from higher education and primary schools.

- Questionnaires are the most common data collection method in these studies.

A study done by Erdogmus and Cagiltay in Turkey in 2009 aimed at revealing the research trends in theses of master's and doctorate degrees in departments of Computer Education and Instructional Technology (CEIT) across Turkey. This study found out that the majority of the theses examined focused on media and media comparison and they mostly used experimental, review and situation analysis methodologies. One other study by Simsek et. al. (2007) in Turkey made a general evaluation of doctoral dissertations completed in the field of educational technologies in the last ten years in five top universities in Turkey. The findings of this research suggest that every two studies out of three were conducted in experimental model and employed medium level statistical techniques; and the remaining were based on general scanning and beginner level statistical techniques. Almost all of these studies were conducted on subjects or participations studying at formal education system, and only few of them were completed in educational environments outside the formal education system. These studies of experimental model generally made use of achievement tests and attitude scales as data collection tool, and the reliability coefficients reported for these studies are generally at medium level. The review studies were based on questionnaire application, examination of case studies and content analysis.

When the above mentioned studies conducted in our country are examined, it is seen that studies done to identify the current trends in educational technologies are done through investigations into the theses completed in the relevant field. In this context, it is considered that collective assessment and content analyses of the articles will significantly contribute to the determination of up-to-date tendencies in the field of educational technologies in our country. Hence, the purpose of this study has been established to reveal the status of studies on educational technologies in Turkey by examining the topics concentrated upon, features of the researchers and methodological dimensions of the articles published in the last two years in our country.

\section{Methodology}

This study has been carried out by using descriptive review model. It covers the works and studies made in the field of Educational Technologies between 2010 and 2011 and published 
in our country. For the study to achieve its goal, the journals containing "Educational Technologies" in their titles and being circulated across Turkey have been covered in this research to better represent the field of educational technologies. In this context, the Turkish Online Journal of Educational Technology, the Journal of Educational Technologies Researches, Contemporary Educational Technology and Educational Technology Theory and Practice journals have been examined. It has been found out that there are total 316 articles published in these journal in the last two years. Out of these articles, the ones working on a sample and having a method have been specified to be covered by this study. Thus, 263 articles have been found to meet all the criteria of this study and been examined.

The content analysis method has been employed for the analysis of the study. The criteria have been determined to address to the sub-problems to this end. In determination of the criteria, the literature has been used and then the criteria have been finalized based on the discussions with the field expert. According to this, the criteria created in this study and themes with respect to the criteria are given Table 1.

\section{Findings}

\subsection{Focal Points of Articles}

The breakdown of research topics focused on by the articles are shown in the Figure 1. According to this finding, it has been determined that the researches conducted in the field of educational technologies focused most on material, method, system, course and program.

It has been seen Figure 1 our investigation that about two thirds of the articles concentrated on material (creation, development, application, assessment). Notably, the studies done on computer aided teaching materials in the past are now replaced with research on online teaching. The articles on learning-teaching methods mostly dealt with computer-aided teaching methods.

The researches classified in method, on the other hand, generally worked on effects of technology-aided applications. A great majority of these studies are experimentally conducted ones.

When we look at the studies done under the titles of system, course and program, we see that they generally assess the efficiency of web-aided applications. It has been seen that the research subjects under the title 'other' dealt with topics such as proficiency, content analysis, ethics, attitude, stress, and so on. The examinations highlight that there are fewer studies conducted on distance education. However, these topics and subjects are always on the global agenda as well as of Turkey, and it is a requirement to determine the principles research-based design, application and assessment compared to face-to-face education in conventional sense.

\subsection{Number of Authors}

Breakdown of number of article authors is given in Figure 2. According to this, the researches in the field of educational technologies have been conducted by mostly one author, two authors, three authors and four authors in decreasing order. 
It has been found out that the number ( $36 \% ; \mathrm{f}=95$ ) of articles with single author is the highest in the studies examined. The number $(32 \% ; \mathrm{f}=86)$ of articles done by two authors is close to those articles with one author. The reason for this might be that the researchers published the articles of their theses together with their advisors in peer-reviewed journals. It is seen that the number (31\%; $\mathrm{f}=82$ ) of researches with three or more authors is quite high. The reason here can be considered as that the project works made at doctoral or master's courses are published as articles.

\subsection{Country of Authors}

Breakdown of articles by the country of each author is given in Figure 3. According to this, it is seen that the researches on educational technologies have been made mostly by Turkish, Taiwanese, Malaysian, U.S., Cypriot and Chinese authors in decreasing order.

Looking at the countries of authors, it is seen that the authors publishing the highest number of articles are from Turkey $(50 \% ; \mathrm{f}=133)$. Turkey is followed by Taiwan $(12 \% ; \mathrm{f}=32)$, Malaysia (7\%; $\mathrm{f}=18)$ and the USA (7\%; $\mathrm{f}=18)$. It has been observed that the number of studies conducted by Taiwanese authors is gradually increasing in the recent years. This situation might be interpreted as originating from the fact that the educational technologies are recently gaining importance in that country. Australia, United Arab Emirates, Nigeria, Korea, Iran and Pakistan fall under the category of other.

\subsection{Countries of Studies}

The Figure 4 shows the countries where the researchers conducted their studies. Since some of the studies have been conducted in more than one country, the total number of countries of the researchers has been found from the total number of articles $(\mathrm{f}=275)$.

When we look at the number of countries where the studies have been conducted, we see that again the country where the highest number of researches has been made is Turkey (52\%; $\mathrm{f}=137$ ). The ordering does not change when it comes to the countries of the researchers and the countries where the researches are done, yet their numbers vary. The number of countries where the research has been conducted differs compared with the countries of the authors. The reason for this fact can be thought as that the academicians and scholars visit different countries for research purposes.

\subsection{Respondents/Participants}

The respondents in the journals examined have been categorized as students, teachers and document analysis. For these categories; the category of students has been created to refer to primary, high school and university students; teachers to refer to pre-school, primary and high school teachers; documents to refer to dissertations, course books, educational CDs, articles, etc. and others to refer to adults, parents, users and other people not falling under any of the above categories. Figure 5 gives the total distribution of respondents in the researches.

As also seen from Figure 5, the results of examinations on types of respondent in the journals show that the studies covered the university students at the most in the last two years $(50 \%$, 
$\mathrm{f}=132)$. The university students are followed by the primary school students $(21 \%, f=55)$ and teachers $(15 \%, \mathrm{f}=40)$ in the researches.

\subsection{Research Paradigm}

263 articles covered by our study have been reviewed by categorizing into three according their research paradigms as qualitative, quantitative and integrated studies containing both qualitative and quantitative methods. Figure 6 is the breakdown of the researches by their paradigms conducted in the last two years.

When we look at the research paradigms used in the articles, we see that 190 articles have employed quantitative (72\%) and 42 articles have employed qualitative (16\%) paradigms to a great extent or in a supportive manner. That means seven of every ten articles have used quantitative models. Moreover, 31 articles have employed both qualitative and quantitative paradigms (12\%).

\subsection{General Pattern}

263 articles covered by this study have been examined under 3 categories according their research models as review, experimental and mixed models where both review and experimental researches have been carried out. Figure 7 is the total breakdown of the researches by their models conducted in the last two years.

When we have a look at the models utilized in the researches conducted in 2010-2011, it is seen that the researches utilized review model at the most in total (76\%; $f=199$ ). This is followed by experimental research model (22\%; $\mathrm{f}=57$ ), and it is seen that the number of mixed models where experimental and review research models have been used together are a few (3\%; f=7).

\subsection{Data Collection Tool}

The 263 articles in our study have been examined by classifying them under 16 categories as questionnaire, scale, test, document analysis, interview form, observation form, daily analysis, recording analysis, video records and web records. Figure 8 is the total breakdown of the researches by the tools used conducted in the last two years.

When examined, it has been seen that scales are the most common data collection tools in these studies (26\%; $\mathrm{f}=68$ ). This result shows that most of these studies have taken the student achievement and skills are a variable. This tool is followed by questionnaire $(21 \% ; f=54)$, various qualitative research forms $(13 \% ; \mathrm{f}=35)$ and testing $(8 \% ; \mathrm{f}=20)$. On the other hand, the majority (33\%; $f=86)$ of the articles investigated have employed one than one data collection tool.

\subsection{Data Analysis Level}

These 263 articles covered by our research have been examined under 3 categories as simple statistics, parametric statistics and non-parametric statics according the analysis methods used. Figure 9 is the total breakdown of the researches by the analysis methods used in the research articles conducted in the last two years. 
The data analysis methods used in those researches reveal that the most common method is parametric data analysis method (48\%; $\mathrm{f}=127)$. Parametric data analysis is followed in order by simple statistics (45\%; $\mathrm{f}=118$ ) and nonparametric statistics methods $(7 \%$; $\mathrm{f}=18)$.

\section{Conclusions and Discussion}

In this study, the research articles published between 2010 and 2011 in four journals selected in order to determine the current situation and trends in the educational technologies. The journals containing "Educational Technology" have been selected for the purposes of this study. The journals determined have been analyzed based on criteria and themes identified by the researchers and the findings have been presented.

Having looked at the focal points of these researches, it has been concluded that the studies have been made on material at the most; and this is followed by studies conducted with a focus in the order on method, system, course and program. It has been determined that the studies with material focus have been made to generate a new material and to find out the educational impacts of the existing materials. The method-oriented studies have attempted to determine the effects of various teaching strategies by taking into account the most learned features. The studies of system focus have used audio-visual technologies and various effects on certain educational structures have been examined.

The countries where the researches have been conducted and the countries of the researchers show similarities and these countries are in the order Turkey, Taiwan, Malaysia, U.S.A., Cyprus, China, United Kingdom and Canada. For the number of authors, the higher number of researchers who have conducted 3 or more studies attracts the attention. This situation may refer to the increasing team work in the field and more joint studies by the researchers in different disciplines and fields. Another reason for this is the publication of assignments given in the courses for project works as articles. The number of researches by two researchers is also quite high. This may be interpreted as resulting from publication of doctoral or master's theses as articles.

Looking at the data collection tools used in the last two years, such tools show varieties. The diversity of tools used in the articles is closely associated with the paradigm used. Use of mainly quantitative paradigm is the reason for utilization of scales and questionnaires as data collection tools.

The models of the researches also show parallelism in parallel to the paradigms used. Considering all the articles examined, the review model is the one mostly used and this is followed by experimental models. Almost 75 percent of the respondents and participants in these researches are students and we have found that more than half of these students are university students. This can be explained by easy access to and availability of university students for the researchers. On the other hand, data analysis methods are parallel to the data collection tools employed. Parametric data analysis methods have been the most commonly used analysis method in the field, and it has been found out that this is followed by simple and nonparametric statistical methods. 


\section{Macrothink}

Journal of Studies in Education

ISSN 2162-6952

2013, Vol. 3, No. 3

\section{References}

AECT. (2004). The meanings of educational technology. Retrieved from http://www.indiana.edu/ molpage/Meanings\%20of\%20ET 4.0.pdf

Alkan, C. (1997). Educational technology (5th ed.). Ankara: Ani.

Caffarella, E.P., \& Sachs, S.G. (1990). Doctoral dissertations in instructional design and technology, 1977 to 1988. Educational Technology: Research and Development, 38(3), 1-13. http://dx.doi.org/10.1007/BF02298180

Caffarella, E.P. (1999) The major themes and trends in doctoral dissertation research in educational technology from 1977 through 1998. Stanford, CA: ERIC Clearinghouse in Information Resources (ED 436178).

Erdogmus, F.U., \& Cagiltay, K. (2009). The general trends in master and doctoral dissertation of educational technologies. Retrieved from http://ab.org.tr/ab09/kitap/_AkademikBilisim09.pdf

Hew, K.F., Kale, U., \& Nari, K. (2007). Past research in instructional technology: results of a content analysis of empirical studies published in three prominent instructional technology journals from the year 2000 through 2004. Journal of Educational Computing Research, 36(3), 269-300. http://dx.doi.org/10.2190/K3P8-8164-L56J-33W4

Simsek, A., Ozdamar, N., Becit, G., Kilicer, K., Akbulut, Y., \& Yildirim, Y. (2008). The general trends in researches on educational technologies in turkey. Selcuk University Journal of Social Sciences Institute, 19, 439-458.

Table 1. Criteria and themes developed in the study

\begin{tabular}{l|l}
\hline Criteria & Themes \\
\hline Focus & $\begin{array}{l}\text { Material, Method, System, Course, } \\
\text { Program, etc. } \\
\text { Number of Authors } \\
\text { Country of Author }\end{array}$ Countries of authors have been specified. \\
Country where Studies Made & Countries where the studies were made \\
& have been specified. \\
Participants & Student, Educator, Specialist, Manager ,etc \\
Paradigm & Quantitative, Qualitative, Mixed. \\
General Pattern & Survey, Experimental, Mixed. \\
Data Collection Tool & Questionnare, Scale, Test, Observation \\
& Form, Interview, etc.. \\
Level of Analysis & Simple, Parametric, Nonparametric. \\
\hline
\end{tabular}




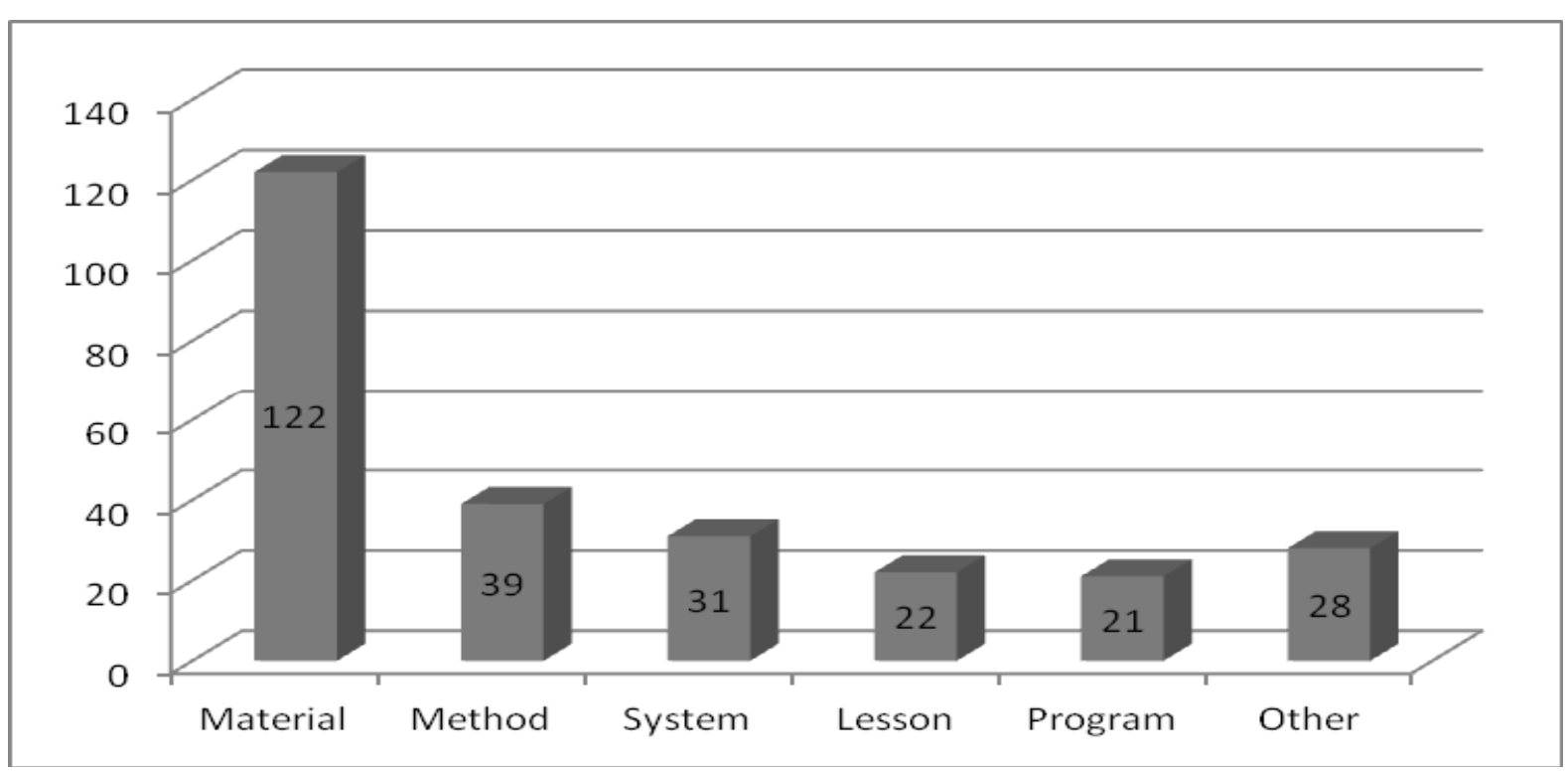

Figure 1. Breakdown of research focuses of articles

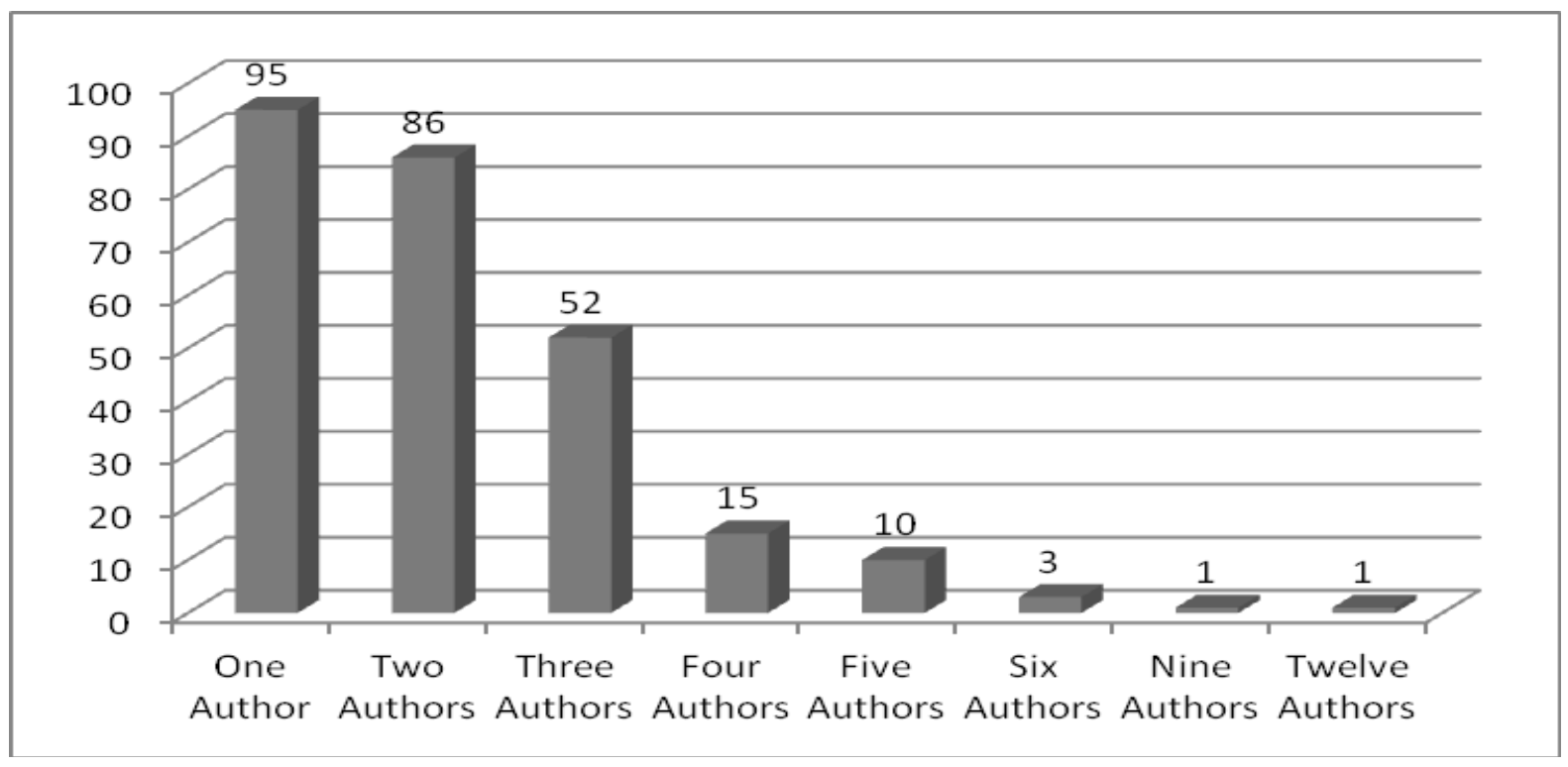

Figure 2. Breakdown of articles by number of authors 


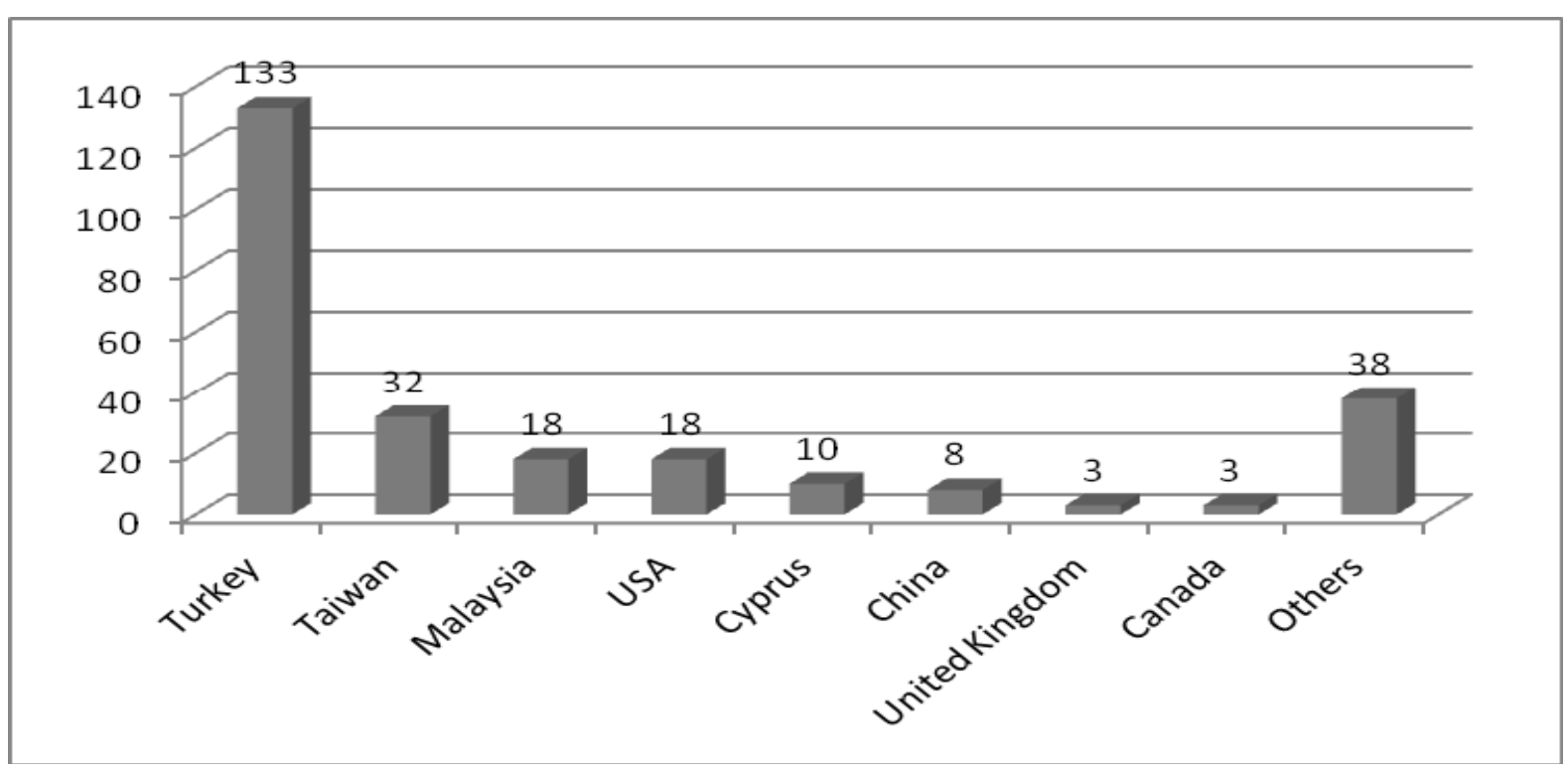

Figure 3. Breakdown of articles by country of authors

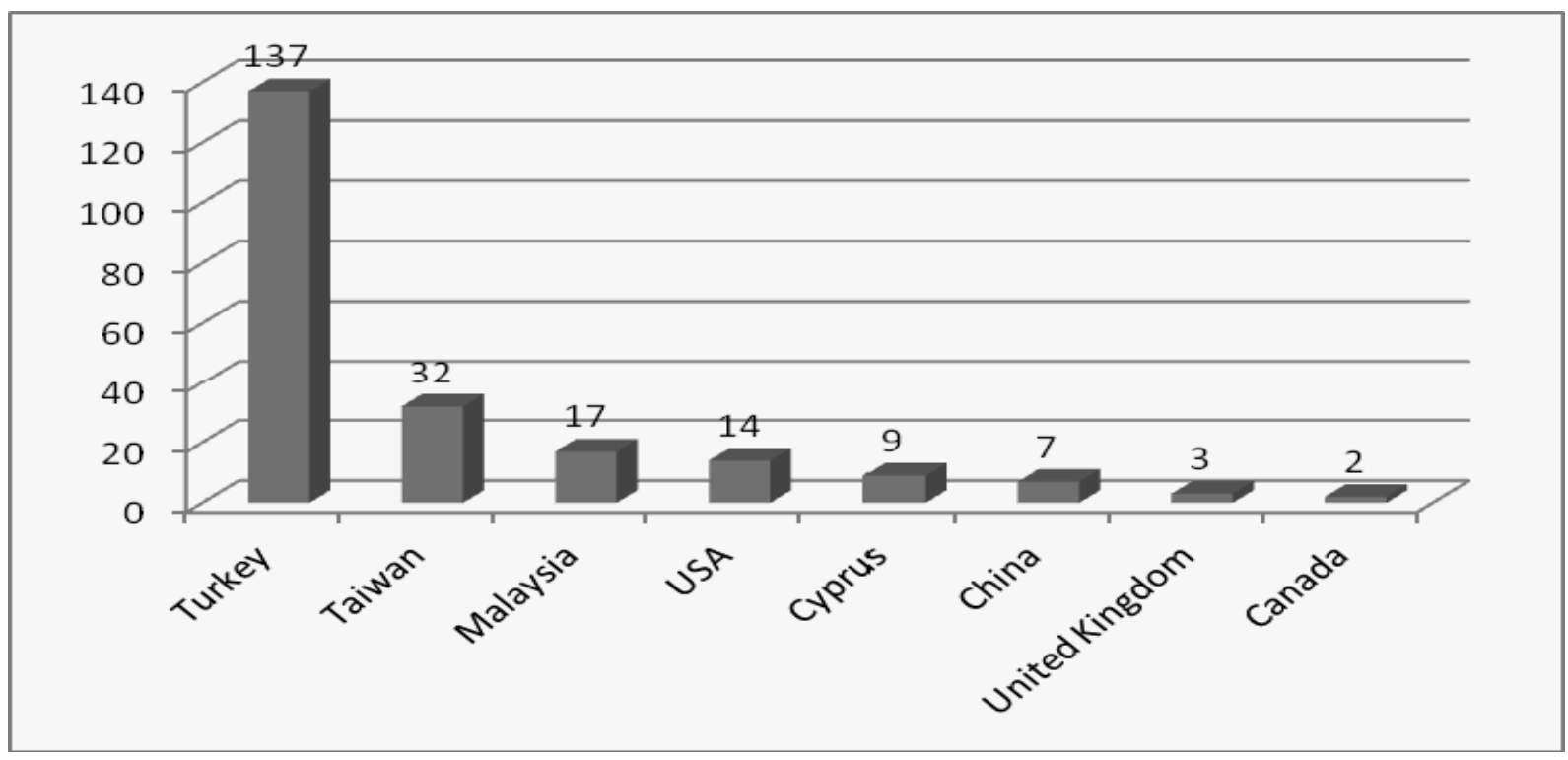

Figure 4. Breakdown of articles by countries 


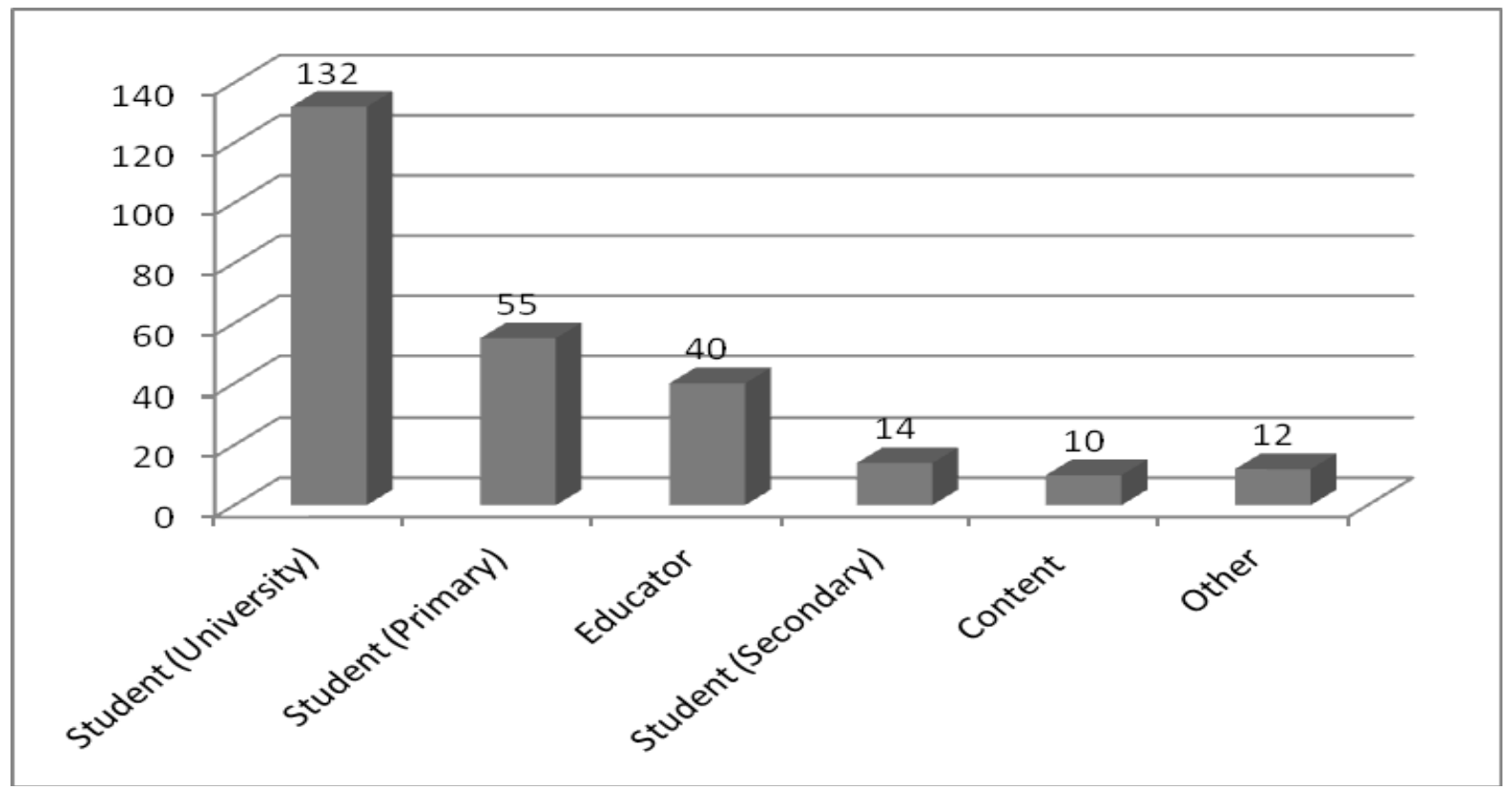

Figure 5. Breakdown of articles by type of respondent

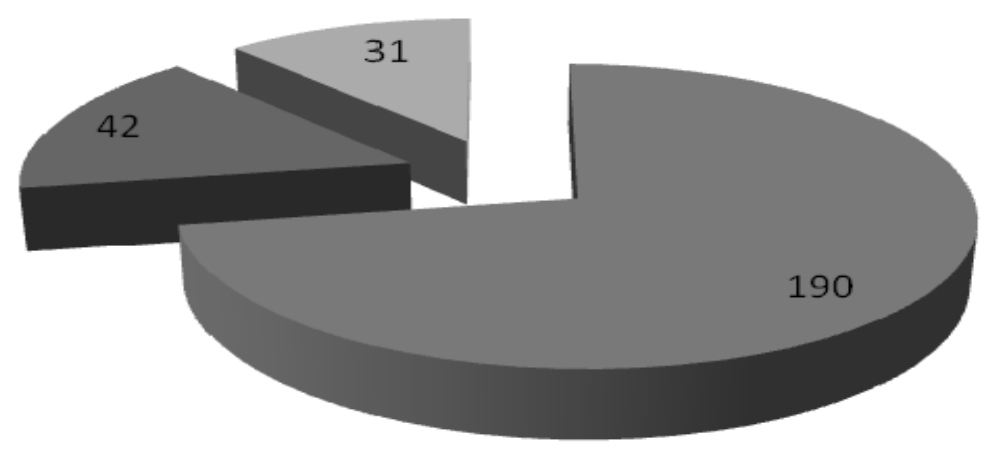

Quantitative

- Qualitative

Mixed

Figure 6. Breakdown of articles by paradigms 


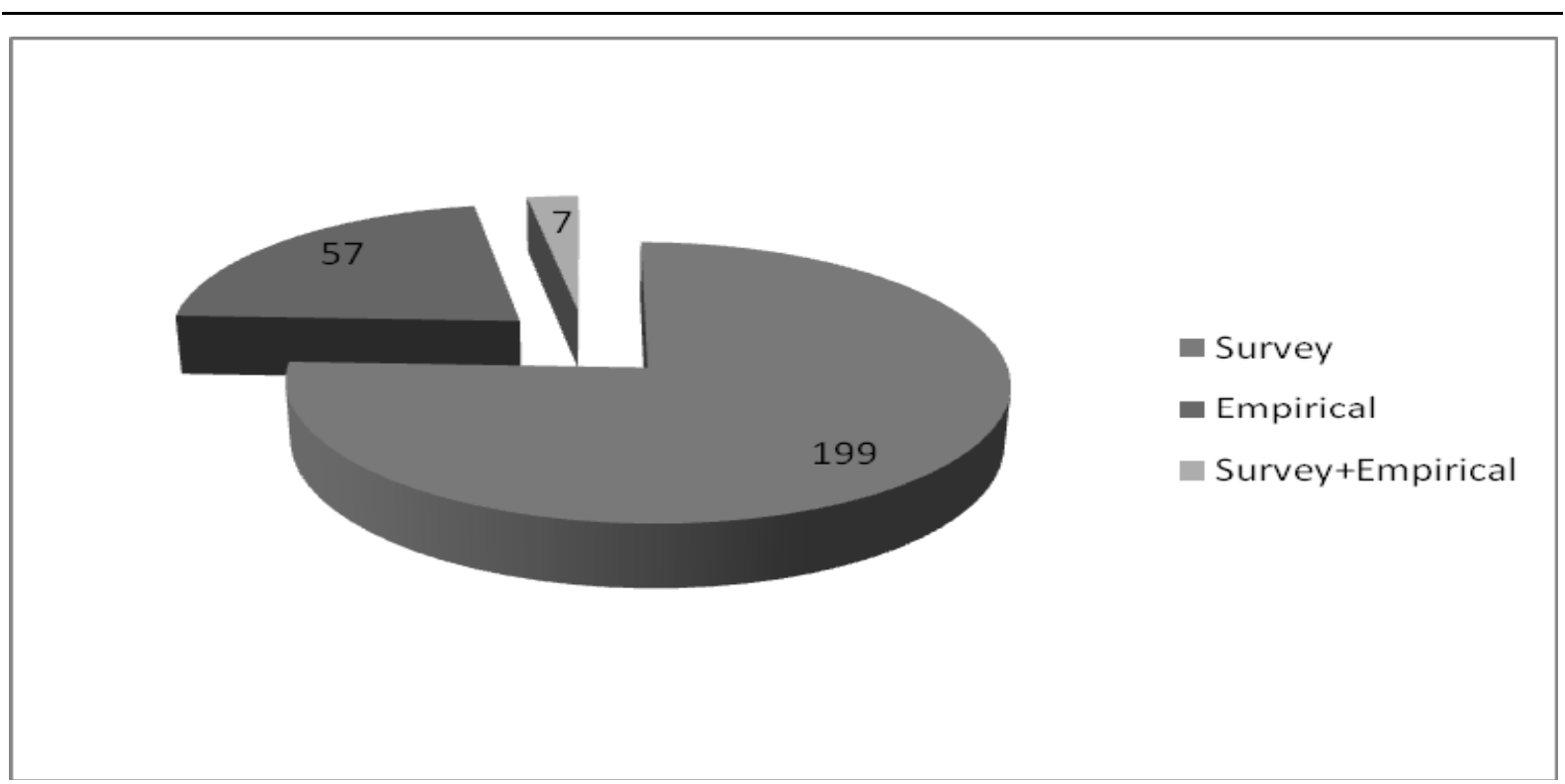
2013, Vol. 3, No. 3

Figure 7. Breakdown of articles by patterns

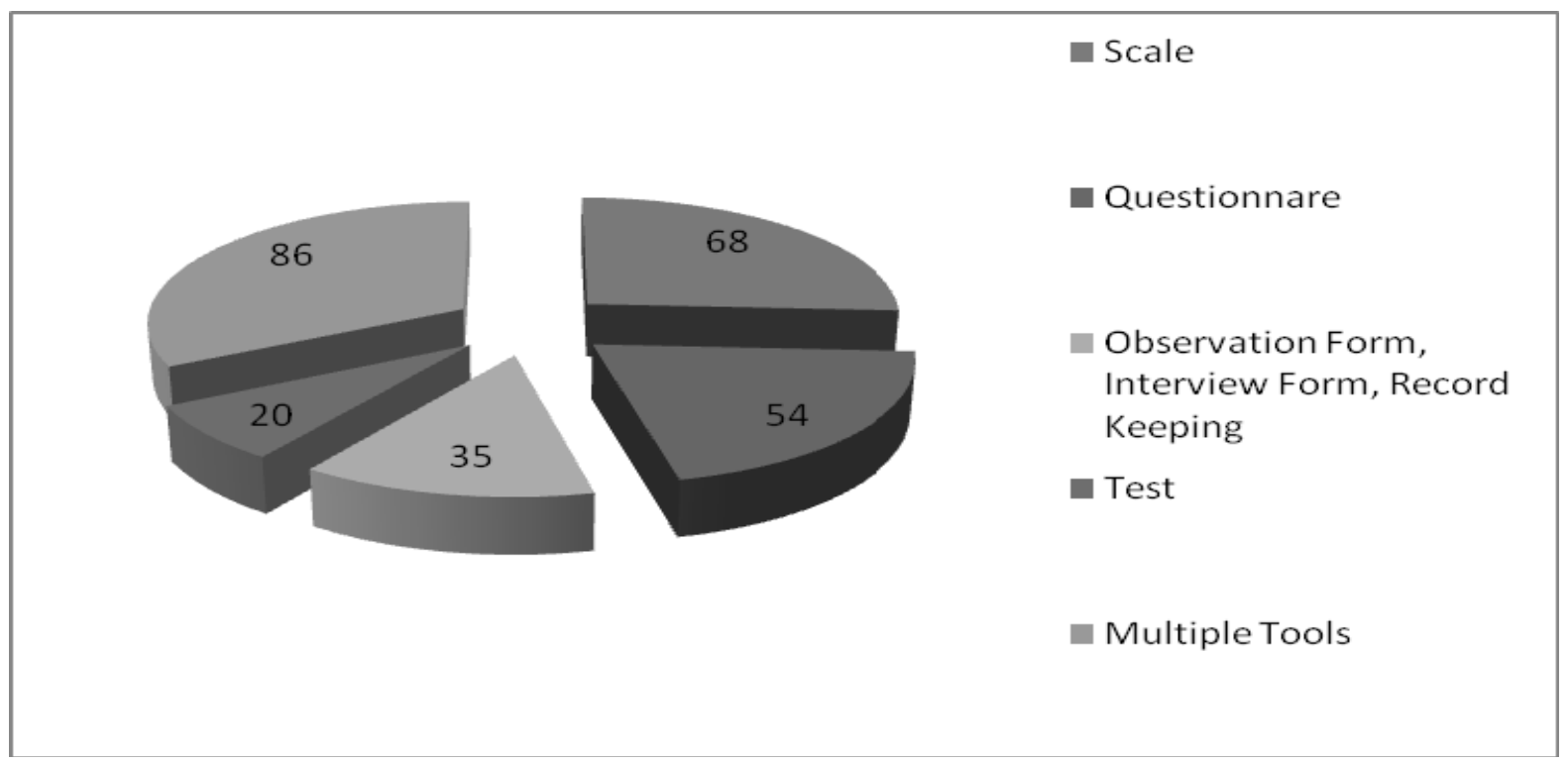

Figure 8. Breakdown of articles by data collection tool 


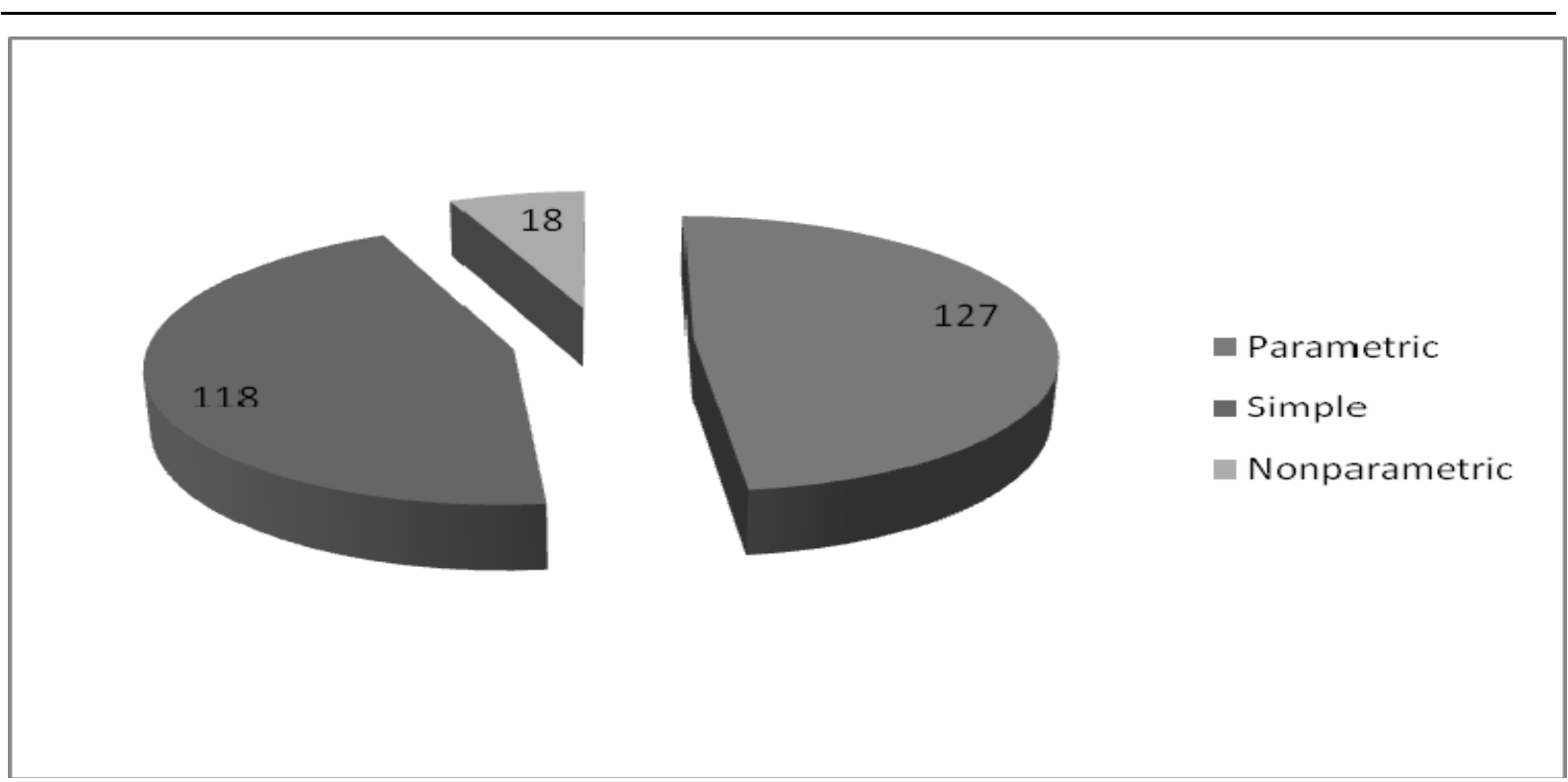

Figure 9. Breakdown of articles by analysis methods 